\title{
Therapy with nCPAP: incomplete elimination of Sleep Related Breathing Disorder
}

\author{
L. Grote*, J. Hedner*, R. Grunstein ${ }^{+}$, H. Kraiczi*
}

\begin{abstract}
Therapy with nCPAP: incomplete elimination of Sleep Related Breathing Disorder. L. Grote, J. Hedner, R. Grunstein, H. Kraiczi. (C)ERS Journals Ltd 2000.

ABSTRACT: Correct assessment of the overall treatment effectiveness requires knowledge about therapy compliance and efficacy. This study aimed to determine overall long-term apnoea alleviation after continuous positive airway pressure (CPAP) in a complete sleep laboratory cohort.

Out of 209 consecutive CPAP candidates (mean age $57 \pm 12$ yrs, body mass index (BMI) $30.0 \pm 5.1 \mathrm{~kg} \cdot \mathrm{m}^{2}$, respiratory disturbance index (RDI) $32.9 \pm 29 \mathrm{~h}$ ), follow-up treatment was performed in 149 of them at 9,18 and 30 months after CPAP prescription. Compliance with CPAP (machine run time/days CPAP available) was adjusted for the individual subjective sleep-time. Apnoea alleviation was defined as adjusted compliance multiplied by the CPAP effect (RDI with CPAP applied), remaining RDI was calculated.

The baseline RDI, age or BMI in 75 patients, who did not tolerate nasal continuous positive airway pressure (nCPAP), did not differ from those accepting CPAP (acceptors, $n=74)$. In acceptors at 9 months follow-up RDI with CPAP applied was $1.4 \pm 2.6$ (CPAP effect, $n=66$ ), mean CPAP use was $3.6 \pm 2.5 \cdot 24 \mathrm{~h}^{-1}(\mathrm{n}=68)$, mean apnoea alleviation was $52.4 \pm 32.0 \%$ (range $1-100 \%, n=47$ ), the average remaining wholenight RDI was $17.8 \pm 26$. At 9,18 and 30 months $(n=47)$, the mean daily CPAP use increased from 3.6 $\pm 2.5 \mathrm{~h}$ to $4.1 \pm 2.5 \mathrm{~h}$ and $4.4 \pm 2.4 \mathrm{~h}(\mathrm{p}<0.01)$.

Effectiveness of continuous positive airway pressure is potentially high but acceptance was low. When accounting for sleep-time, its actual effect and use, only $\mathbf{5 0 \%}$ adjusted continuous positive airway pressure effectiveness was observed.

Eur Respir J 2000; 16: 921-927.
\end{abstract}

\begin{abstract}
*Dept of Clinical Pharmacology and Sleep Laboratory, Sahlgrenska University Hospital, Göteborg, ${ }^{+}$Sleep Disorders Centre, Royal Prince Alfred Hospital, Camperdown, Sydney 2050, Australia.
\end{abstract}

Correspondence: L. Grote, Dept of Clinical Pharmacology, Sahlgrenska University Hospital, Gothenburg, Sweden. Fax: 4631826723

Keywords: Compliance

continuous positive airway pressure

effectiveness

efficacy

sleep apnoea

sleep apnoea alleviation

Received: September 91999

Accepted after revision June 102000

This study was supported by the Carnegie Foundation and the Swedish Heart and Lung Foundation.
Nasal continuous positive airway pressure (nCPAP) is the standard therapy in obstructive sleep apnoea (OSA). When used at an appropriate level continuous positive airway pressure (CPAP) therapy almost always leads to complete elimination of sleep related respiratory disturbance in OSA patients. However, a number of practical problems limit the capacity of CPAP to eliminate sleep related breathing in patients.

Compliance with CPAP has been determined in a number of different ways. Most groups have calculated compliance by describing the actual number of hours per night or per week the CPAP device has been used [1]. "Cut-off points" describing certain hours of nightly CPAP use have been described by other investigators. Some of these "cut-off points" have been set at arbitrary levels [2], based on median group values [3], or based on outcome data related to sleepiness and performance [4]. It has also been suggested that compliance is better defined by CPAP use in relation to total subjective sleep-time. Using this approach, CPAP was used for $44 \%$ up to $68 \%$ of time subjects were estimated as being asleep $[5,6]$. Although good CPAP compliance is frequently defined as usage $>5 \mathrm{~h} \cdot$ night $^{-1}$ for at least 5 days.week ${ }^{-1}$, the impact of treatment may be highly different when comparing a patient sleeping $5 \mathrm{~h} \cdot$ night $^{-1}$ with another with a habitual 8 h sleep-time.
Another important issue to consider in CPAP use is actual efficacy of therapy. Compliance does not necessarily equal efficacy. Recent data from a study of CPAP therapy outcomes showed that many subjects will comply with CPAP even if it is deliberately set at a subtherapeutic level [7]. Therefore, it is important to obtain measures of efficacy as well as compliance in determining CPAP use in patients with OSA.

The aim of this study was to examine CPAP acceptance, compliance (with and without consideration of total sleep time) as well as monitoring efficacy in a complete cohort of patients in the authors' healthcare area.

\section{Methods}

\section{Patients}

This retrospective study included 149 consecutive patients referred to the sleep laboratory at Sahlgrenska University Hospital, with suspected OSA. This centre was the sole prescriber of CPAP units in the Gothenburg healthcare area (population approximately 1,000000). Male and female patients aged $20-80$ yrs were included. The indication for CPAP treatment was based on clinical symptoms and severity of the sleep related breathing 
disorder. In the study population $(n=149), 94 \%$ of patients had an RDI $\geq 5$ and $83 \%$ of $\geq 10$, respectively. The remaining $6 \%$ were diagnosed with increased upper airway obstruction followed by frequent arousal. The study group represented an unselected group of patients identified by clinicians for CPAP therapy and may therefore, be claimed to closely reflect clinical practice at the hospital. Sixty patients from an adjacent healthcare area were not included in the analysis.

\section{Questionnaire}

A standardized, structured questionnaire including mean self-reported sleep-time during the night as well as items of professional activity, family relations, and previous and present health problems was routinely completed by all patients at baseline. Snoring as well as the presence or absence of witnessed apnoeas were recorded. Daytime symptoms including sleepiness (sleepiness score) and feeling refreshed after sleep (morning alertness score) were determined using a scale ranging from 0 (never) to 5 (very often) [8]. Information regarding alcohol $\left(\mathrm{mg} \cdot \mathrm{week}^{-1}\right)$ and smoking (cigarette consumption. day $^{-1}$ ) habits was obtained.

\section{Sleep study}

The sleep studies (baseline/CPAP titration/follow-up) took place in the hospital sleep laboratory. Oxygen saturation was measured with pulse oximetry, oronasal airflow with thermistors, respiratory movements using a sensitive charge bed [9] or the Edentec $\mathbb{R}$ system [10]. Signals were amplified and classified via a computer program. Results were scored manually using standardized criteria for sleep related breathing disorders [11]. Apnoea was defined as cessation of airflow for at least $10 \mathrm{~s}$ together with a dip in the arterial oxygen saturation $\left(\mathrm{Sa}, \mathrm{O}_{2}\right)$ of $\geq 4 \%$. Hypopnoea was defined as a reduction in airflow of at least $50 \%$ in relation to the immediately preceding baseline combined with a dip in $\mathrm{Sa}_{2} \mathrm{O}_{2}$ of $\geq 4 \%$. At CPAP follow-up the nasal airflow signal was exchanged for a CPAP pressure signal. Only full night studies with a minimum of $5 \mathrm{~h}$ self-reported sleep-time were accepted. The calculated mean respiratory disturbance index (RDI) was based on the number of respiratory events. $\mathrm{h}^{-1}$ of self-estimated sleep. The minimum overnight $\mathrm{Sa}, \mathrm{O}_{2}$ was determined.

\section{CPAP titration}

The diagnosis of OSA as well as the rationale and principle of CPAP therapy was carefully explained to each patient. Practical use of the CPAP equipment was demonstrated during a daytime nursing staff session. Each patient underwent a whole-night sleep study for titration of CPAP pressure. Titration was started at a pressure of 5 $\mathrm{cmH}_{2} \mathrm{O}$ and progressively increased by $1 \mathrm{~cm} \mathrm{H} \mathrm{H}_{2} \mathrm{O} \cdot 10 \mathrm{~min}$ until apnoeas, hypopnoeas and snoring were eliminated. On the following morning the patient met the sleep specialist for further information. It was specifically stressed that continuous use of CPAP every night was necessary in order to eliminate OSA and related daytime symptoms. Patients were instructed to return the CPAP if they did not wish to continue using the device.

\section{Follow-up}

Data was collected from patient files or obtained from the sleep laboratory computer data base. The targeted recruitment period covered January 1, 1994-December 31, 1994. Follow-up data were collected until September 30, 1998. Age, sex, and body mass index (BMI) were recorded for each patient at study entry. Subjective sleep-time with CPAP was retrospectively assessed in 43 patients after 3 yrs of therapy by a questionnaire.

In order to ensure compliance, to identify potential problems related to the therapy, and to encourage CPAP use all patients were contacted at 2 weeks after initiation of CPAP therapy. A CPAP follow-up including a clinical visit and a sleep study was performed at 9 months $(n=86), 18$ months $(n=68)$ and 30 months $(n=47)$ after start of therapy. The study flow chart is depicted in figure 1 . The total time (h) of CPAP use (built-in counter for CPAP run-time), applied CPAP pressure, and the number of nights since CPAP prescription were recorded for each follow-up visit. Patients underwent a full night study with CPAP applied and met the sleep specialist on the following morning. OSA alleviation was calculated from adjusted compliance and CPAP efficacy at 9 months follow-up (RDI from sleep study with CPAP applied). The parameter was expressed as remaining RDI and as \% of alleviated total sleep apnoea activity during the follow-up period. Table 1 contains the recorded and calculated data as well as a description of the applied terminology. Patient outcome is described in figure 1. CPAP nonacceptors were defined as patients who returned their CPAP device at any stage of the follow-up during 30 months $(n=75)$. The remaining patients were defined as acceptors $(n=74)$. In non-acceptors 24 patients attended the follow-up program at 9 months and underwent a full night study with CPAP applied at a set pressure. At 9 months, effectiveness data were missing in $16 \%$ of the patients who accepted CPAP $(n=12)$, and in $17 \%$ of the patients who did not $(n=4)$.

The complete analysis of the effectiveness, compliance and OSA alleviation with CPAP therapy was affected by missing data caused by technical error (sleep study), incomplete questionnaires or lack of information in medical history. In three patients the CPAP blower was exchanged during the follow-up period and actual CPAP running time was not retrieved. Six patients lacked one follow-up visit but they reappeared at the next control.

Compliance data were missing in 6 acceptors $(8 \%)$, and OSA alleviation data were missing in 27 acceptors (36\%). Compliance data at 9, 18 and 30 months of follow-up was obtained in 47 patients and OSA alleviation data in 37 patients, respectively (fig. 1).

\section{Statistics}

Statistical analysis was performed using the SPSS software program (SPSS for windows 7.5, Chicago, Illinois). Results are given as mean \pm SD. All reported pvalues are two-tailed. Pearson's correlation coefficient was used to analyse the association between RDI and age, BMI, blood pressure, CPAP pressure and to determine the correlation between CPAP compliance, adjusted CPAP compliance and OSA alleviation. A student's t-test was performed to investigate the differences in antropometric 


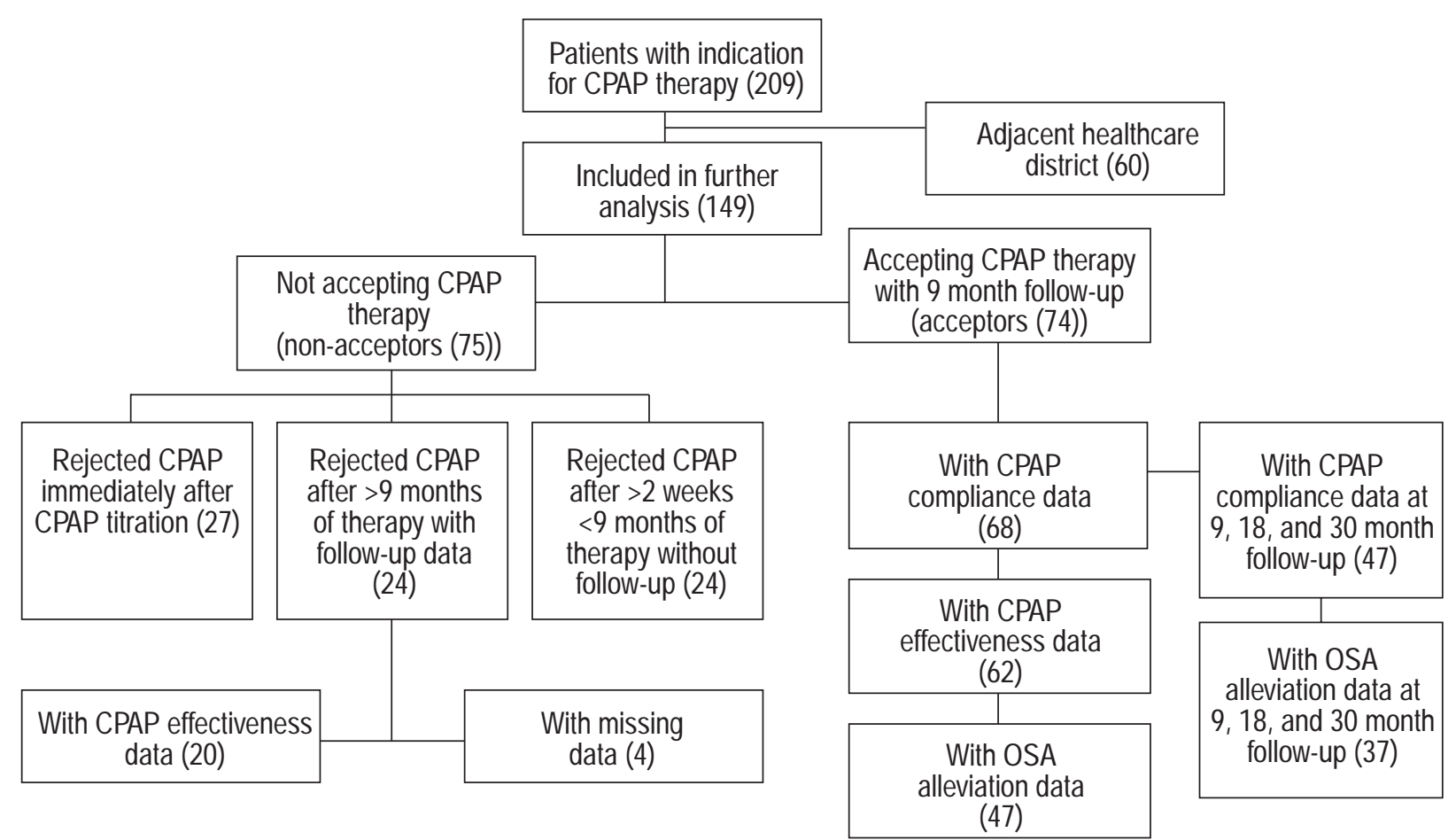

Fig. 1. - Flow chart of the study sample. Number of patients are shown in parentheses. CPAP: continuous positive airway pressure; OSA: obstructive sleep apnoea.

and sleep related data between CPAP acceptors and nonacceptors. Paired samples t-test was used to evaluate differences in CPAP use after 9, 18, and 30 months.

\section{Results}

Seventy-four patients $(50 \%$ of patients with follow-up data) tolerated CPAP as a long-term therapy of OSA (acceptors), while 75 patients rejected CPAP use (nonacceptors). Out of the non-acceptors 27 patients refused immediately upon CPAP titration, 24 patients after $>2$ weeks experience at home but before the first follow-up visit at the sleep laboratory and 24 patients after having attended one or more follow-up visit. Subjectively reported sleep-time in acceptors was $0.6 \mathrm{~h}$ shorter than in nonacceptors, but this difference as well as other sleep data and antropometric data (table 2) did not reach statistical significance.
OSA activity at baseline, expressed as RDI, correlated significantly with age $(\mathrm{r}=0.16, \mathrm{p}<0.05)$, BMI $(\mathrm{r}=0.3$, $\mathrm{p}<0.01)$, diastolic blood pressure $(\mathrm{r}=0.27, \mathrm{p}<0.05)$ and subsequently titrated CPAP pressure $(r=0.37, p<0.01)$ whereas sleepiness and morning alertness scores, CPAP compliance, and systolic blood pressure did not. Mean self-reported sleep-time at baseline in 149 patients was $6.9 \pm 1.8 \mathrm{~h}$ and did not correlate with RDI ( $\mathrm{r}=-0.26$, Ns).

In patients with sleep laboratory follow-up at 9 months, residual RDI with CPAP applied was almost identical in acceptors and non-acceptors, $1.4 \pm 2.6, \mathrm{n}=66$ and $0.5 \pm 0.7$, $\mathrm{n}=20$, respectively. Compliance with CPAP, expressed as the calculated mean CPAP usage in hours, was 3.6 \pm 2.5 $\mathrm{h} \cdot 24 \mathrm{~h}^{-1}$ in CPAP acceptors and $0.9 \pm 1.0 \mathrm{~h}$ in non-acceptors. Adjusted compliance, expressed as mean \% daily use of CPAP after correction for sleep-time, was $56.0 \pm 33 \%$ of total sleep-time in acceptors (fig. 2). Compliance and adjusted compliance were highly correlated $(\mathrm{r}=0.94$,

Table 1. - Applied measures in the evaluation of continuous positive airway pressure

\begin{tabular}{|c|c|c|c|}
\hline Investigation/tool & Recorded variables & Calculated variables & Assessed factor \\
\hline Baseline sleep study & RDI (baseline) & & \\
\hline Control sleep study (CPAP) & $\begin{array}{l}\text { RDI (CPAP); Days of } \\
\text { CPAP available }\end{array}$ & $\begin{array}{l}\text { RDI (baseline) - RDI } \\
\text { (CPAP applied) }\end{array}$ & CPAP-effect \\
\hline Build in time counter (CPAP) & CPAP run time & $\begin{array}{l}\text { CPAP run time/days of } \\
\text { CPAP available }\end{array}$ & CPAP compliance \\
\hline Questionnaire at baseline & $\begin{array}{l}\text { Subjective sleep-time } \\
\text { during night }\end{array}$ & $\begin{array}{l}\text { CPAP compliance/subjective } \\
\text { sleep-time }\end{array}$ & Adjusted CPAP compliance \\
\hline All of above & & $\begin{array}{l}\text { Adjusted CPAP compliance } \times \\
\text { CPAP-effect* }\end{array}$ & $\begin{array}{l}\text { OSA alleviation } \\
\text { a) RDI reduction (\%) from baseline RDI } \\
\text { b) remaining RDI with CPAP applied }\end{array}$ \\
\hline
\end{tabular}

*: bRDI-(\% CPAP use $\times($ bRDI $\times(1-R D I$ with CPAP/bRDI $))$ ). CPAP: continuous positive airway pressure; RDI: respiratory disturbance index; bRDI: baseline respiratory distrubance index. 
Table 2. - Antropometric and sleep data

\begin{tabular}{lcc}
\hline & $\begin{array}{c}\text { CPAP } \\
\text { acceptors }\end{array}$ & $\begin{array}{c}\text { CPAP non- } \\
\text { acceptors }\end{array}$ \\
\hline Subjects & 74 & 75 \\
Age yrs & $57 \pm 12$ & $56 \pm 12$ \\
BMI kg·m & $29.7 \pm 5.1$ & $30.3 \pm 5.1$ \\
Systolic BP mmHg & $144.0 \pm 17.1$ & $141.4 \pm 21.5$ \\
Diastolic BP mmHg & $84.3 \pm 13.1$ & $85.4 \pm 11.2$ \\
Smoking cigarettes·day ${ }^{-1}$ & $2.0 \pm 0.6$ & $1.9 \pm 0.6$ \\
Alcohol mg.week & $168 \pm 73$ & $175 \pm 83$ \\
RDI $\mathrm{h}^{-1}$ & $35.1 \pm 30.9$ & $31.4 \pm 26.4$ \\
Lowest $\mathrm{Sa}_{2} \mathrm{O}_{2} \%$ & $71.9 \pm 15.2$ & $76.9 \pm 10.2$ \\
Sleepiness score & $3.5 \pm 1.2$ & $3.5 \pm 1.1$ \\
Morning alertness score & $2.5 \pm 1.0$ & $2.4 \pm 1.1$ \\
Sleep-time $\mathrm{h}$ & $6.7 \pm 2.0$ & $7.3 \pm 1.0$ \\
CPAP pressure after CPAP & $8.6 \pm 2.5$ & $8.4 \pm 2.2$ \\
titration night $\mathrm{cmH}_{2} \mathrm{O}$ & & \\
\hline
\end{tabular}

Data are presented as mean \pm SD. BMI: body mass index; RDI: respiratory disturbance index; $\mathrm{BP}$ : blood pressure; $\mathrm{Sa}_{\mathrm{a}, \mathrm{O}_{2}}$ : arterial oxygen saturation; CPAP: continuous positive airway pressure.

$\mathrm{p}<0.001)$. At 3 yrs follow-up mean subjective sleep-time with CPAP was unchanged $(6.6 \pm 2.0$ versus $6.6 \pm 1.4$, $\mathrm{p}=0.97$ ), the individual differences between the baseline and follow-up sleep-time (mean $0.01 \pm 1.2 \mathrm{~h}$ ) were not correlated with age, BMI, RDI, sleepiness at baseline or measures of CPAP use $(p>0.4)$.

Sleep apnoea alleviation, expressed as the \% overall calculated reduction from baseline RDI, was $52.4 \pm 31.7 \%$ in acceptors $(\mathrm{n}=47)$ (fig. 2). The calculated residual mean RDI with CPAP was $17.8 \pm 26.1 \mathrm{n} \cdot \mathrm{h}^{-1}$. Compliance and $\%$ OSA alleviation were significantly correlated $(\mathrm{r}=0.93$, $\mathrm{p}<0.001$ ), but showed remarkable individual differences (fig. 3). The \% OSA alleviation was slightly better correlated to CPAP acceptance than CPAP compliance ( $\mathrm{r}=0.4$, $\mathrm{p}=0.002$ versus $\mathrm{r}=0.38, \mathrm{p}=0.004$, respectively). Out of the 47 acceptors only $18(38.2 \%)$ reached more than $75 \%$ OSA alleviation. When considering the whole group prescribed CPAP $(n=149)<20 \%$ of patients had more than $75 \%$ OSA alleviation.
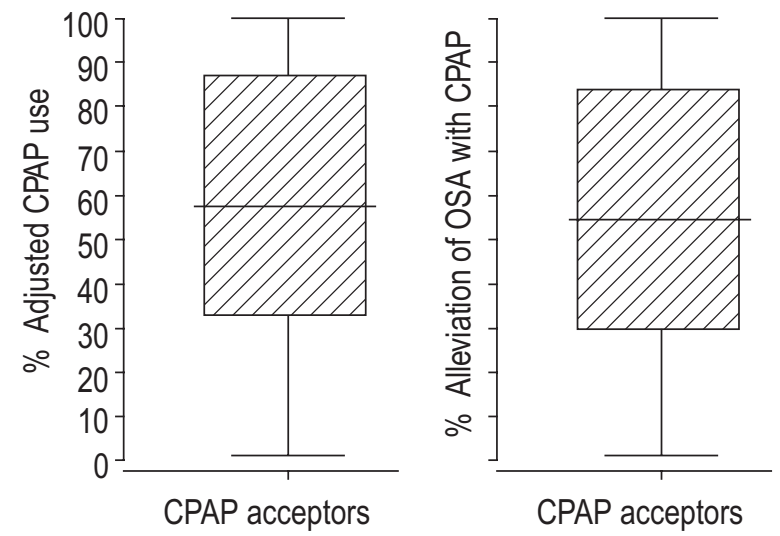

Fig. 2. - Adjusted CPAP compliance (CPAP compliance/sleep-time) in CPAP acceptors $(n=50)$ and \% OSA alleviation (adjusted CPAP compliance $\times$ CPAP effect) with CPAP at 9 months follow-up in CPAP acceptors $(n=47)$. Shown is a box and whisker plot indicating the upper and lower quartile $(\mathbb{Z})$ with the median (central line). The points at the whisker are the 2.5 and $97.5 \%$ values. CPAP: continuous positive airway pressure; OSA: obstructive sleep apnoea.

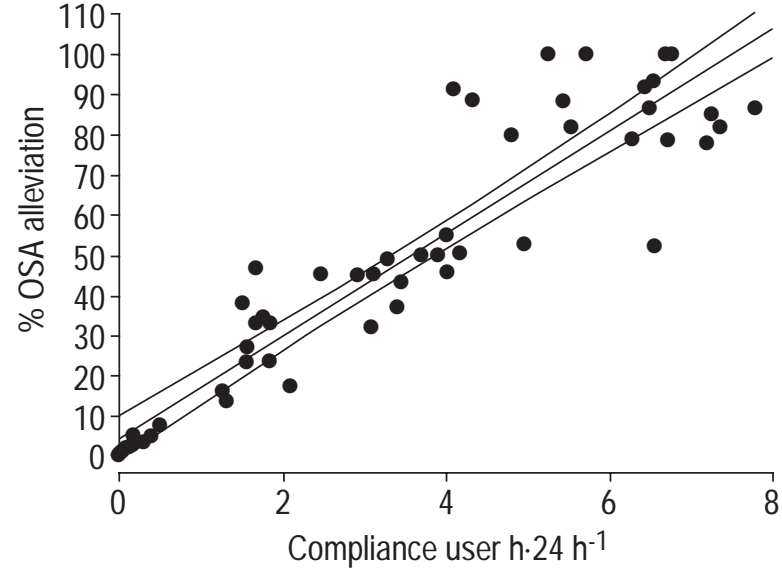

Fig. 3. - Individual OSA alleviation (adjusted CPAP compliance $\times$ CPAP effect) in 58 patients at 9 months after initialization of CPAP therapy in relation to CPAP compliance expressed as user $h \cdot 24 \mathrm{~h}^{-1}$. The linear regression line $\left(r_{2}=0.86\right)$ and $95 \%$ confidence interval is shown. OSA: obstructive sleep apnoea; CPAP: continuous positive airway pressure.

Long-term follow-up after 9, 18 and 30 months in 47 CPAP acceptors demonstrated that compliance, expressed as mean CPAP use $\cdot 24 \mathrm{~h}^{-1}$, increased $(\mathrm{p}=0.01)$ from $3.6 \pm 2.5$ $\mathrm{h} \cdot 24 \mathrm{~h}^{-1}$ to $4.1 \pm 2.5 \mathrm{~h} \cdot 24 \mathrm{~h}^{-1}$ and $4.4 \pm 2.4 \mathrm{~h} \cdot 24 \mathrm{~h}^{-1}$, respectively (fig. 4), resulting in an increased proportion of apnoea alleviation $(\mathrm{p}<0.01)$ from $52.4 \pm 31.7 \%$ to $59.7 \pm$ $29.7 \%$ and finally $62.4 \pm 31.0 \%$.

\section{Discussion}

The clinical outcome of patients first prescribed CPAP in the Gothenburg Area in 1994 have been described. Of these 149 patients, half had returned their CPAP machines and did not accept continuation of therapy. In patients continuing to use CPAP, compliance was variable and it appears that CPAP therapy has a lower overall treatment effectiveness in OSA patients than previously suggested.

The authors believe this is the first study to describe the acceptance rate, long-term compliance and OSA alleviation in a clearly defined clinical cohort. The centre in this

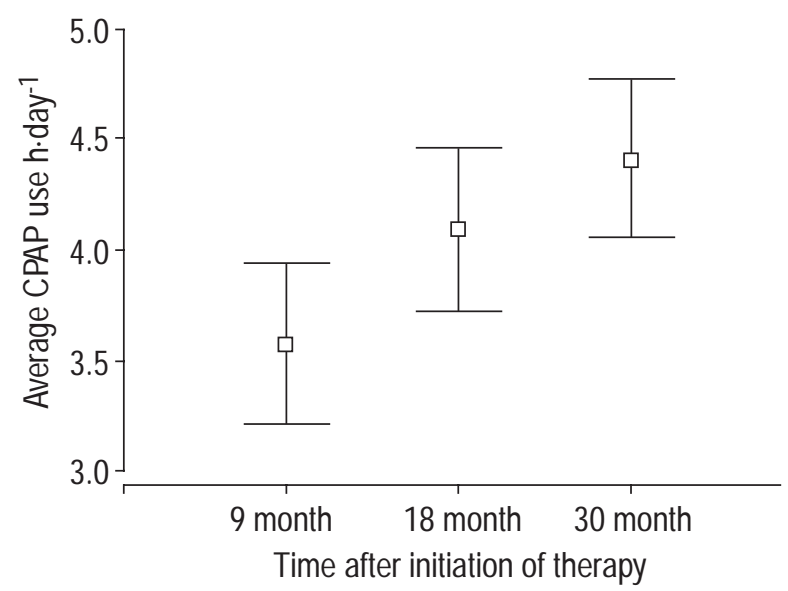

Fig. 4. - Average daily CPAP use after 9, 18 and 30 months in CPAP acceptors investigated at all three time points $(n=47)$. CPAP: continuous positive airway pressure. 
study provides CPAP for all treatment candidates residing in the greater Gothenburg area and the studied cohort represents all CPAP prescriptions in this region of Sweden for one year. As part of the national healthcare system, patients were provided with machines at no cost. Sleep studies and follow-up were fully subsidized. Therefore, there was no financial disincentive to CPAP acceptance.

The acceptance rate of CPAP in the patient group was low (50\%). A recent large French survey reported that $86 \%$ of patients accepted CPAP as treatment for sleep apnoea [12]. However, this figure was based on a $60 \%$ response rate and it was not possible to assess the true number of patients who were initially prescribed CPAP but refused therapy at an early stage. Similar acceptance rates to the data in this study were reported by RAUSCHER et al. [13], although their figure was obtained after the first night of therapy. The low acceptance rates may in part be explained by the availability and promotion of alternative therapies. In case of remaining non-acceptance with CPAP, second-line therapy was offered: oral appliances (16 cases), participation in an intense diet program (10 patients), upper airway (5 patients) or other type of surgery (1 patient facial surgery, 1 patient gastroplastic surgery), and body positional measures (2 cases). 3 patients restarted nasal ventilation with nasal bilevel positive pressure ventilation (BIPAP). The remaining 30 patients refused to participate in a follow-up program. However, the centre did not have a dental device program in 1994 and surgery was recommended according to accepted international criteria. Therefore, the low CPAP acceptance rate does not appear to be attributed to specific local conditions.

Previous studies have suggested that acceptance is mainly determined by the degree of daytime sleepiness, severity of OSA or other polysomnographic parameters, educational level and age $[1,12,14]$. No such predictors were found in this study. This may be due to the smaller cohort size. However, repeated sleep studies performed during follow-up established that CPAP continued to be effective at the prescribed pressures. Even in the subgroup of non-acceptors who attended the full 9 month follow-up period, failure of CPAP to eliminate the breathing disorder did not account for non-acceptance.

In patients accepting CPAP, the overall calculated longterm proportion of time with apnoea alleviation was approximately $50 \%$ with a range $1-100 \%$. Moreover, patients who were frequent users of CPAP, and therefore likely to have benefit from therapy, tended to increase the use of CPAP over time. The average daily hours of CPAP use is frequently used to express compliance. When applying arbitrary cut-off points for the average daily use of CPAP (e.g. $\left.\geq 5 \mathrm{~h} \cdot \mathrm{day}^{-1}\right)$ to define compliance, previous studies found it to range $50-90 \%[2,15,16]$. However, there is no general consensus on the cut-off point for acceptable compliance [17]. In a recent French study [12] following-up 3,225 patients, mean hours of CPAP use was approximately $6.5 \mathrm{~h}$ in patients accepting treatment. A lower level of use, between $4.7 \mathrm{~h}$ and $5.9 \mathrm{~h}$, was found in another patient group even though they received different measures aimed at improving compliance [18]. A study by EngLEman et al. [19] reported a low $(4.3 \pm 0.6 \mathrm{~h})$ CPAP run-time in users without reported therapy related problems and an even lower one $(2.8 \pm 0.6$ $\mathrm{h}$ ) in those complaining of side-effects. Additionally, a recent study reported daily CPAP use $(3.9 \pm 0.4)$ at similar levels to the data produced in this study for patients who received standard support for nCPAP therapy [20]. Compliance with CPAP therapy was related to the amount of OSA activity, the severity of daytime sleepiness, as well as the diagnostic follow-up procedure used. But no such correlation was demonstrated in this study cohort, although a wide spectrum of sleep disordered breathing severity and daytime symptoms were studied. .

These studies demonstrate several problems associated with CPAP trials. Firstly, patients who are early nonacceptors of therapy may be analysed in some studies but not in others. Secondly, there appears to be a high interstudy variation in user time and this may be influenced by a number of factors including the method of assessment, study population, intensity of follow-up and reimbursement issues. Even if CPAP use may be relatively high, true alleviation of sleep disordered breathing depends on actual time asleep. ReEves-Hoche et al. [5] calculated compliance by dividing machine run-time by reported hours of sleep. They identified a number of individuals in their study who had ceased CPAP use during the night and then continued to sleep. These investigators reported that CPAP running time was $66 \%$ of the reported sleep-time in continuing users at 28 week follow-up. More recently, other workers observed that patients with mild to moderate degrees of OSA used CPAP for less than half of their total sleep-time [6]. In addition, sleep duration after CPAP initiation was significantly reduced in long sleepers [21]. A shortening of mean sleep-time after CPAP would result in an underestimation of the "true" OSA alleviation with CPAP. To control for this effect, the subjective sleep-time before and after CPAP in a subgroup of patients was compared. Although no significant difference was found, this underestimation of overall CPAP effectiveness may have occurred in individual patients. In three patients the OSA alleviation index was above 100\% (101-103\%), which may be explained by this effect or by the fact that the blower was running without being connected to the patient. The discordant results of the study cited above may be due to the fact that it was a short-term follow-up study (up to 3 months) and having specifically focused on the sleep-time of long-sleepers.

A new parameter, OSA alleviation, which adjusted for subjectively assessed sleep-time and the untreated residual degree of sleep apnoea at follow-up, was introduced in this study. Using this measure approximately $40 \%$ of acceptors, but less than $20 \%$ of the patients originally prescribed CPAP, have at least $75 \%$ of their sleep related breathing disorder treated effectively. The estimated remaining mean RDI was approximately 17 after 9 months in this study. This corresponds to a 50\% reduction compared with the baseline and by far exceeds the RDI of 5 which is typically claimed as a cut-off point for sleep apnoea in most epidemiological studies. Considering systemic hypertension, which has a focus for treatment for more than $60 \mathrm{yrs}$ and has well defined criteria for diagnosis and disease control, this study raises the question "How much therapy is enough to control symptoms and cardiovascular risk of sleep apnoea?" Previous data demonstrates that CPAP treatment leads to control the symptoms of OSA and to improve the patients quality of life [22]. These studies do not necessarily control for remaining RDI under therapy but the relief of symptoms may be 
sufficient as an outcome variable. Moreover, improvement of driving performance after initiation of nCPAP therapy has never been assessed in the view of a threshold for remaining sleep apnoea activity. Again, the relief of symptoms may be sufficient. In this context it may be speculated that remaining RDI under CPAP is an important determinant for the extent of a preventive effect. Two large cross-sectional studies have demonstrated an independent dose-response relationship between RDI and systolic/diastolic blood pressure [23, 24]. As for cardiovascular morbidity and mortality in OSA, there is increasing evidence, that nCPAP may have beneficial effects [7, 25-27]. However, these effects have never been controlled for measures of OSA alleviation with therapy. Furthermore, other treatment modalities such as upper airway surgery which are described as less effective than CPAP may actually compare favourably with CPAP under these circumstances as surgery has "complete compliance" for obvious reasons. It may be speculated that actual OSA alleviation may prove to be a useful parameter in future outcome research in OSA superior to mean CPAP user time. However, these issues have to be clarified in further prospective studies.

It should be borne in mind that determining OSA alleviation has its limitations. Firstly, subjective sleep-time may lead to under- or overestimation of true sleep-time. However, in comparison studies with wrist-actigraphy, there was an approximately 93\% concordance between actigraphic sleep-wake state and subjective sleep-time reports [28]. Another potential limiting factor is the use of CPAP run-time to determine compliance. Previous studies have demonstrated that run-time reflects only $89-97 \%$ of the use time with effective mask pressure [2, 19]. Finally, calculating OSA alleviation requires information from several sources including sleep studies, questionnaires, medical history, and the CPAP built-in time counter, and this increases the probability of data loss.

The retrospective study design led to a large amount of missing data in the determination of OSA alleviation and CPAP effectiveness, especially in patients rejecting CPAP therapy. This limits the statistical power of analysis and therefore, the interpretation and generalization of data especially regarding the reasons for non-acceptance of CPAP therapy. This indicates the necessity for further prospective studies applying OSA alleviation as an indicator variable for overall CPAP effectiveness. However, prospective compliance studies in CPAP may be inherently biased by eliminating potential non-acceptors prior to any CPAP trial or having treatment protocols which are not clinically realistic. This potential problem has been recognized in prospective, randomized clinical trials for the treatment of patients with cancer, systemic hypertension, or heart failure [29, 30].

Several measures to improve CPAP use have been investigated. Frequent phone calls for positive reinforcement after CPAP prescription did not improve compliance [31]. In contrast, CHERvin et al. [18] found a significant improvement following written information or regular phone calls. The present data suggests that regular followup in CPAP acceptors also improves outcome during an extended time period. CPAP usage after 18 and 30 months was increased compared to after 9 months. The finding is likely to be biased by the fact, that patients in these extended follow-up groups were better CPAP users and had become more self selecting over time, whereas non compliant patients had terminated therapy after this long period of non-use. This result can therefore, only be applied to compliant patients and not extrapolated to all CPAP users. However, the findings support the maintenance of an intensive follow-up programme after an extended treatment period.

In conclusion, this study, which may be limited by its retrospective design, loss of data and a relatively small number of patients, demonstrated that continuous positive airway pressure has a potentially high efficacy, which leads to almost complete elimination of apnoea. However, in this clinically based cohort of patients with indications of continuous positive airway pressure the overall treatment effectiveness was approximately 50\% with a long-term acceptance of only $50 \%$. Determination of the overall effectiveness of CPAP (apnoea alleviation) which accounts for sleep-time, user hours and efficacy may provide a parameter which leads to new insights into the impact of treatment in obstructive sleep apnoea. In the selected group of long-term users a regular follow-up program appeared to result in improved continuous positive airway pressure use.

\footnotetext{
Acknowledgements. The authors wish to thank J. Norum for collecting the data and her
} assistance in further analysis.

\section{References}

1. Grunstein M. Sleep-related breathing disorders. 5. Nasal continuous positive airway pressure treatment for obstructive sleep apnoea. Thorax 1995; 50(10): 11061113.

2. Kribbs NB, Pack AI, Kline LR, et al. Objective measurement of patterns of nasal CPAP use by patients with obstructive sleep apnea. Am Rev Respir Dis 1993; 147: 887-895.

3. Engleman HM, Martin SE, Deary IJ, Douglas NJ. Effect of CPAP therapy on daytime function in patients with mild sleep apnoea/hypopnoea syndrome. Thorax 1997; 52(2): 114-119.

4. Engleman HM, Kingshott RN, Wraith PK, Mackay TW, Deary IJ, Douglas NJ. Randomized placebo-controlled crossover trial of continuous positive airway pressure for mild sleep apnea/hypopnea syndrome. Am J Respir Crit Care Med 1999; 159(2): 461-467.

5. Reeves-Hoche MK, Meck R, Zwillich CW. Nasal CPAP: an objective evaluation of patient compliance. $\mathrm{Am} \mathrm{J}$ Respir Crit Care Med 1994; 149(1): 149-154.

6. Redline S, Adams N, Strauss ME, Roebuck T, Winters M, Rosenberg C. Improvement of mild sleep-disordered breathing with CPAP compared with conservative therapy. Am J Respir Crit Care Med 1998; 157: 858-865.

7. Jenkinson C, Davies RJO, Mullins R, Stradling J. Comparison of therapeutic and subtherapeutic nasal continous positive airway pressure for osbtructive sleep apnoea: a randomised prospective parallel trial. Lancet 1999; 353(9170): 2100-2106.

8. Partinen M, Gislason T. Basic Nordic Sleep Questionnaire (BNSQ): a quantitated measure of subjective sleep complaints. J Sleep Res 1995; 4: 150-155.

9. Polo O, Brissaud L, Sales B, Besset A, Billiard M. The validity of the static charge sensitive bed in detecting obstructive sleep apnoeas. Eur Respir J 1988; 1: 330336. 
10. Emsellem HA, Corson WA, Rappaport BA, Hackett S, Smith LG, Hausfeld JN. Verification of sleep apnea using a portable sleep apnea screening device. South Med J 1990; 83: 748-752.

11. Association of Sleep Disorders Centres. Diagnostic classification of sleep and arousal disorders. Sleep 1979; 2: 1-122.

12. Meslier N, Lebrun T, Grillier-Lanoir V, et al. A French survey of 3,225 patients treated with CPAP for obstructive sleep apnoea: benefits, tolerance, compliance and quality of life. Eur Respir J 1998; 12(1): 185-192.

13. Rauscher H, Popp W, Wanke T, Zwick H. Acceptance of CPAP therapy for sleep apnea. Chest 1991; 100: 10191023.

14. Bennett LS, Langford BA, Stradling JR, Davies RJ. Sleep fragmentation indices as predictors of daytime sleepiness and nCPAP response in obstructive sleep apnea. Am $J$ Respir Crit Care Med 1998; 158(3): 778-786.

15. Sanders MH, Gruendl CA, Rogers RM. Patient compliance with nasal CPAP therapy for sleep apnea. Chest 1986; 90: 330-333.

16. Krieger J. Long-term compliance with nasal continuous positive airway pressure (CPAP) in obstructive sleep apnea patients and nonapneic snorers. Sleep 1992; 15: S42-S46.

17. McNicholas WT. Compliance with nasal CPAP therapy for obstructive sleep apnoea: how much is enough? Eur Respir J 1997; 10: 969-970.

18. Chervin RD, Theut S, Bassetti C, Aldrich MS. Compliance with nasal CPAP can be improved by simple interventions. Sleep 1997; 20(4): 284-289.

19. Engleman HM, Martin SE, Douglas NJ. Compliance with CPAP therapy in patients with the sleep apnoea/hypopnoea syndrome. Thorax 1994; 49(3): 263-266.

20. Hoy CJ, Vennelle M, Kingshott RN, Engleman HM, Douglas NJ. Can intensive support improve continuous positive airway pressure use in patients with the sleep apnea/hypopnea syndrome? Am J Respir Crit Care Med 1999; 159: 1096-1100.

21. Pepin JL, Krieger J, Rodenstein D, et al. Effective compliance during the first 3 months of continuous positive airway pressure. A European prospective study of 121 patients. Am J Respir Crit Care Med 1999; 160(4): 1124-1129.

22. Bennett LS, Barbour C, Langford B, Stradling JR, Davies RJO. Health status in obstructive sleep apnea. Am J Respir Crit Care Med 1999; 159: 1884-1890.

23. Young T, Peppard P, Palta M, et al. Population-based study of sleep-disordered breathing as a risk factor for hypertension. Arch Intern Med 1997; 157(15): 1746-1752.

24. Grote L, Ploch T, Heitmann J, Knaack L, Penzel T, Peter JH. Sleep-related breathing disorder is an independent risk factor for systemic hypertension. Am J Respir Crit Care Med 1999; 160(6): 1875-1882.

25. Peker Y, Kraiczi H, Hedner J, Loth S, Johansson A, Bende M. An independent association between obstructive sleep apnoea and coronary artery disease. Eur Respir J 1999; 14(1): 179-184.

26. Peker Y, Hedner J, Johansson A, Bende M. Reduced hospitalization with cardiovascular and pulmonary disease in obstructive sleep apnea patients on nasal CPAP treatment. Sleep 1997; 20(8): 645-653.

27. He J, Kryger MH, Zorick FJ, Conway W, Roth T. Mortality and apnea index in obstructive sleep apnea. Experience in 385 male patients. Chest 1988; 94: 9-14.

28. Usui A, Ishizuka Y, Obinata I, Okado T, Fukuzawa H, Kanba S. Validity of sleep log compared with actigraphic sleep-wake state. Psychiatry Clin Neurosci 1998; 52(2): 161-163.

29. Britton A, McKee M, Black N, Mcpherson K, Sanderson C, Bain C. Threats to applicability of randomised trials: exclusions and selective participation. J Health Serv Res Policy 1999; 4(2): 112-121.

30. Remington RD. Potential impact of exclusion criteria on results of hypertension trials. Hypertension 1989; 13(5 Suppl): I66-I68.

31. Fletcher EC, Luckett RA. The effect of positive reinforcement on hourly compliance in nasal continuous positive airway pressure users with obstructive sleep apnea. Am Rev Respir Dis 1991; 143: 936-941. 